\title{
Scaffolding Online Collaborative Critiquing for Educational Video Production
}

\section{Yiong Hwee Teo}

Education Technology Division, Ministry of Education

1 North Buona Vista Drive, Singapore 138675

E-mail: yhteo3@gmail.com

\section{Ching Sing Chai*}

National Institute of Education, Nanyang Technological University, 1 Nanyang Walk, Singapore 637616

Fax: 65-68968038 E-mail: chingsing.chai@nie.edu.sg

*Corresponding author

\begin{abstract}
In art, design and media education, learning from examples has been an established way to coach students. To derive greater benefits, teachers should get students to go beyond mere studying of examples. This paper focuses on engaging novice learners in collaborative critiquing of real examples of professional work and past student work in the context of producing an educational video project. While critiquing of such works is not new in art education, there is however scant literature on how to involve students in collaborative critiquing in an online environment involving video projects. A four-step critique model was therefore designed as procedural scaffolding and implemented in an online system, Knowledge Community. A group of Singapore pre-service teachers were engaged in online collaborative critiquing of videos before they embarked on their video projects to illustrate what constitutes good and bad video production. This research points to the value of online collaborative critiquing as a way to facilitate novice designers' progress towards expertise. In this environment learners are able to look at problems through multiple perspectives, generate their own solutions and build knowledge that uses the overlapping expertise of the online community.
\end{abstract}

Keywords: Online discussion, Examples, Critiquing, Video production

Biographical notes: Yiong Hwee Teo is a Lead Specialist at the Ministry of Education (Singapore) in Educational Technology. His specialty is in the area of educational video production and his research interest is in computersupported collaborative learning, critical thinking and online discussion.

Ching Sing Chai is an assistant professor at the National Institute of Education, Learning Sciences and Technologies Academic Group. His research interest is in the field of teachers' beliefs and computer-supported collaborative learning. 


\section{Introduction}

Producing videos can be a powerful learning experience (Jonassen, Howland, Marra, \& Crimsond, 2008). However, to produce a good video requires producers to possess many forms of skills and knowledge. Teaching skill-based subjects such as video production therefore poses a challenge: how can the learners understand and apply the principles and grammar of video production in their work? To establish standards in project-based learning, researchers such as Thomas and Mergendoller (2000) recommended the use of examples from professional work and previous student work. The use of examples have also been advocated by many researchers (Hoadley \& Kim, 2003; Sweller \& Cooper, 1985) to help learners to gain expertise, particular in the fields of mathematics, physics and computer programming. Teaching using examples involves showing students worked solutions or completed designs. Textbook writers often use worked examples as a kind of modelling to illustrate how certain principles and concepts can be applied. This facilitates understanding for novices whose knowledge schema are not yet well developed and hence, experience difficult times in integrating and applying newly learnt principles. Worked examples are like case libraries that can scaffold memory by providing representations of experiences that learners have not had (Hernandez-Serrano \& Jonassen, 2003).

However, simply observing examples is not sufficient as the benefits of learning from examples depends on how students study them (Conati \& Vanlehn, 2000). For example, studies in cognitive science suggest that students who spontaneously selfexplain when they study examples learn more (Chi \& Bassok, 1989). The authors recommend that students critique actual examples collaboratively before they embark on their design projects.

This paper focuses on engaging novice learners in collaborative critiquing of real examples of professional work and past student work in the context of producing an educational video project. It begins by examining how critiquing helps in learning with reference to its familiar use in art education. It then describes the rationale behind developing a four-step critique model in scaffolding novices for video production. Next, it suggests why critiquing should be done collaboratively in a community and how collaborative critiquing can be achieved through an online discussion forum. This is followed by an empirical research that contributes to the understanding of how online collaborative critiquing of worked examples assisted learners in their learning. Implications for the application of the critique model are also drawn for other subjects such as languages, literature and teacher education modules.

\subsection{How critiquing helps in learning}

What is critique? The sixth edition of the Collins English Dictionary defines critique as "a critical essay or commentary especially on an artistic work; the act or art of criticizing", and the Random House Webster's College Dictionary (second edition) defines criticize as "to judge or discuss the merits of; to make judgements as to merits and faults". Making judgements, according to the Bloom's taxonomy, is the highest level of intellectual activity which pre-supposes that the one critiquing has good knowledge of the subject matter. While critiquing helps to deepen one's understanding, it is not an easy task for novices.

How should critiquing be carried out? The scant literature on critiquing comes from the field of art criticism. In art education, students need to critique examples from the masters as well as their own work and the work of other students (Barrett, 2000; Feldman, 1994). Critiques are used to judge the students' progress by engaging the 
different perspectives of the instructor, the student artist's peers and the student of the artwork. It aims to expand the student's "visual and aesthetic awareness and reinforce that which has just been learned" (Hartung, 1995 , p. 36). By recognising the strengths and weaknesses of other people's work, students can make efforts to improve their artwork (Reist, 2005). Similarly in teaching skill-based subjects such as video production, critiquing examples can alert the learner to designs that work or do not work which can then help to improve the students' design work; it is also less expensive than learning from mistakes and hence can be a more efficient method of learning.

To criticise artwork, Trumbo (1997) suggested a three-step critique process that involved description, interpretation and evaluation which is largely similar to the most cited Feldman (1994) method consisting of four-steps:

1. Description (listing what an art object seems to include).

2. Analysis (describing the relationship among the art elements).

3. Interpretation (deciding the meaning of the preceding observation).

4. Judgement (deciding the value of the art in terms of its merits and faults).

It is unclear whether Feldman's approach can be applied to critiquing the video medium as video differs from the traditional arts in that it encompasses the extra dimensions of time, motion, and sound. This prompted the first author to formulate a four-step critique procedure to teach the production process of video based on his teaching experience in this area.

\subsection{The 4-step critique model for video production}

The four-step critique procedure consists of:

1. Participants identify project purpose, audience and expertise

2. Participants evaluate strengths of design and suggest improvements

3. Participants evaluate weaknesses of design and suggest improvements

4. Participants summarise important points for transfer to own project

The rationale supporting the four-step critique model is now elaborated.

Step 1: Participants identify project purpose, audience and expertise

Step 1 of the critique process involves identifying the instructional goal and analysing the learners. Before any fair critique can be made of a video design, information such as the purpose of the video, the target audience, and the expertise of the production team would be useful. This will enable critics to assess whether the video has achieved its intended objectives set by the production team for its target audience. It would be useful if such information is shared with participants before the critique session wherever possible. Participants are then required to infer whether the example for critique has achieved its stated purpose for the target audience.

Step 2: Participants evaluate strengths and suggest improvements

The heart of critique is judging the merits and faults of the design. It is about evaluating the success or failure of the artefact based on knowledge of design principles, production realities and audience characteristics (Trumbo, 1997). After understanding the intended purpose and target audience of the design project (Step 1), critics can then start to identify how successfully the producer has achieved these aims. The reasons why it is recommended for students to identify strengths before weaknesses are twofold. The first reason concerns critique etiquette. It is more polite and positive to highlight the positive points first. The second reason stems from the first author's experience in conducting critiques. Students normally find it easier to identify weaknesses of a design thereby overlooking the strengths. Critics would need to identify and justify why certain 
attributes are strengths. They can then proceed to suggest improvements to the video or improvements to their peers' comments.

Step 3: Participants evaluate weaknesses and suggest improvements

This step calls for participants to contribute their opinions on what they viewed are shortcomings in the design. These opinions would have to be supported with justifications to add depth to the discussion. Improvements to the video product or peers' suggestions can then be made.

Step 4: Participants summarise important points for transfer to own project

The fourth step of the critique process requires participants to synthesize the comments of peers in the preceding three steps in the form of a summary. The practice of summarizing is widely supported in the field of higher education and within business and industry (Powers, 1992; Reid, 2002). Discussion summaries provide readers with a quick and efficient way to synthesize key points raised. Solutions to various design problems can then be evaluated and prioritised in terms of importance and practicality. Through the discussion summary, students are encouraged to transfer what they have learnt from the critique to their own production.

The four-step critique model aims to provide students with the required procedural scaffolding on how to proceed with the process of critiquing a video. This procedural scaffolding is like a site map which gives learners a sense of the scope and process of critiquing. To derive greater benefit, critique can be done collaboratively instead of individually.

\subsection{Why critiquing should be done collaboratively}

The strength of critiquing or discussing collaboratively lies in the amalgamation of different perspectives and mutual negotiation producing reasoning (Schwartz, 1995). The cognitive diversity and prompted argumentation within such a critique forum encourages learners to build connections between previously possessed knowledge to socially negotiate and mutually learn from peers who possess overlapping areas of expertise.

Collaborative critiquing is underpinned by social constructivism and situated cognition theories. Social constructivism is commonly linked to Vygotsky (1978) because he emphasized the importance of interaction with people, such as other children, parents and teachers, in cognitive development. Learners bring their own thinking and perspective when they interact with others. In return, they also perceive a problem from multiple perspectives. Meaning-making is refined through shared understanding. As a result, learners broaden their own understanding, which is then individually reconstructed using prior knowledge and experience (Wu, 2003). Evolving from social constructivism, situated cognition or situated learning suggests that learning is naturally tied to authentic activity and context (Brown, Collins, \& Duguid, 1989). Context refers to the norms, culture and value of a community. Situated cognitivists argue that learning needs to consider not just the individual learner, but learning as it happens in a group and the setting in which the learning occurs. Available tools and social interactions can significantly shape problem tasks and thinking. Learners learn from the socio-cultural community in which they participate. This process accounts for the way a newcomer to a community develops into a full participant where the learner becomes increasingly competent in the practice of the community (Lave \& Wenger, 1999). Collaboration leads to the articulation of strategies which can enhance students' understanding. Having discussed the merits of collaborative learning, it is timely to explore how technology can be used to facilitate collaborative critiquing.

\subsection{Scaffolding Collaborative Critiquing with Technology}


This study uses asynchronous (different time) online discussion (AOD) to support collaborative learning. An AOD environment can reduce social barriers (Groeling, 1999; Hsi, 1997) and students would be less afraid to "make mistakes", and offer constructive feedback to one another. In general, AOD research suggests the following key benefits to learners (Chai \& Tan, 2006; Guzdial \& Turns, 2000; Wang \& Wu, 2007; Jonassen et al., 2008).

1. Participation can occur at any place and any time thus removing the constraint of limited classroom instruction time and allowing for greater learning flexibility

2. Social barriers due to shyness, language problems or gender are reduced

3. Learners can tap into each others' experiences and expertise to provide peer tutoring and mutual support. By discussing with others, students learn from diverse perspectives making their learning, community-centred

4. The time-delayed text-based interaction in an online environment promotes student's reflection and is learner-centred

However, researchers has also pointed out that it is often necessary to provide appropriate scaffolding for AOD to be fruitful (Chai \& Tan, in press; Ng, Cheung, Hew, in press).

\subsection{Scaffolding in online discussion}

Different researchers have contributed to the literature of scaffolding for online discussion (ibid) since the early works of Guzdial's (1994) "software-realized scaffolding". Guzdial suggested three roles software could play to provide scaffolding: (a) communicating processes where presentation and demonstration by the instructor are contextualised for the learners, (b) coaching learners with hints and reminders about their work, and (c) eliciting articulation from learners to encourage reflection.

Different tools have been used to guide students to participate in online discussions. Examples of such support features include sentence openers students can use to begin their message writing (Guzdial \& Turns, 2000; Scardamalia \& Bereiter, 1991), software coaches offering adaptive help during a learning conversation (Cook, 2000; Howe \& Tolmie, 1998) and turn-taking mechanisms to keep a conversation from running out of synch (Moore, 1993). In this paper, we focus on the use of sentence openers as the main form of scaffold.

Sentence openers can serve as metacognitive scaffolding and strategic scaffolding. Sentence openers are pre-defined ways to start a contribution, and are usually followed by additional text to complete the student's thought (Lazonder, Wilhelm, \& Ootes, 2003). Metacognitive scaffolding such as "this theory cannot explain"; "a better theory" could be useful in helping students in theory building (Scardamalia \& Bereiter, 2006). In addition, sentence openers such as "An alternative way would be" can also prompt students on different ways to do a task. This is akin to strategic scaffolding.

The effects of scaffolds vary according to the different contexts. For example, Chai and Tan (in press) report that having an experienced facilitator is essential to scaffold participants towards in-depth online discussion. On the other hand, $\mathrm{Ng}$ and her colleagues (in press) discover that scaffolding ill-structured problems through sentence openers and message labels may not be effective. They suggest that the message labels and sentence openers have to be carefully designed based on Socratic questioning. Given this background, it seems that more research is needed for educators to better understand the use of scaffolds in a variety of contexts. 


\subsection{Context of Study}

This qualitative case study involved studying a group of 42 pre-service teachers engaged in an online critique of video examples to acquire video production knowledge at the National Institute of Education, the sole teacher training institution in Singapore.

\section{The Elective Unit}

The participants enrolled in the Diploma in Education programme to become primary school teachers and their ages ranged from 21 to 40 . The elective unit was designed and taught by the authors and spanned a period of twelve weeks. The purpose of the unit was to equip these future teachers with the skills and knowledge of educational video production so that they can integrate video snippets in their teaching. There were three learning components: face-to-face lessons (weeks one to seven), online discussion (weeks eight to ten), and group video project work (weeks nine to twelve). The face-toface two-hourly lessons were on design principles of video production. The online discussion component involved an online critique of two video examples. For the group project, participants worked in self-formed groups of three to four members, handling roles such as script writer, cameraman and editor. This study focuses on the online discussion of the video production.

\section{The Online Critique Component}

Participants engaged in online collaborative critique of two videos before they embarked on their group video projects. The video, Strangers was a past year student project depicting three scenarios where a young child was approached by strangers. The other video, No Looking Back was a professional video produced by the Ministry of Education, Singapore. It portrayed two stories on gangsterism in Singapore schools. The two videos were given to participants in the sixth week on a video compact disc to facilitate easy rewind and playback. Participants collaboratively critiqued the videos using a web-based threaded asynchronous discussion platform, Knowledge Community, $(K C)$. The next section describes some obstacles of asynchronous online discussion and how certain features were designed to address them in $K C$.

\subsection{Designing scaffolding to address three obstacles of AOD}

Research on asynchronous online discussion (e.g., Guzdial \& Turns, 2000) suggests that participants face obstacles such as (a) unmotivated by discussion topic, (b) not knowing what issues to discuss and (c) not knowing how to discuss.

Unmotivated by discussion topic

For the problem, "Unmotivated by discussion topic", the authors heeded Guzdial and Turns' (2000) suggestion to use a worked example for students to critique as a way to introduce an anchor topic. As students needed to produce a similar video project at the end of the module, this critique exercise would therefore be authentic, interesting and beneficial to them. The collaborative critique required participants to identify strengths and weaknesses of the two videos, and summarise key ideas that they could incorporate in their own production.

To address the next two problems, "Not knowing what issues to discuss" and "Not knowing how to discuss", relevant scaffolds were explored within $K C$. Hill and Hannafin (2001) advanced a scaffolding framework for use in the digital age in what they termed "resource-based learning environments". Their four key scaffolding components are:

1. Conceptual Scaffolding: Assist the learners in deciding what to consider or to priortise what is important. 
2. Procedural Scaffolding: Assist with how to use a resource.

3. Metacognitive Scaffolding: Assist with establishing what is known and how to think.

4. Strategic Scaffolding: Offer alternative ways to do a task.

The next segment explains how conceptual and procedural scaffolding can be used to support asynchronous discussion.

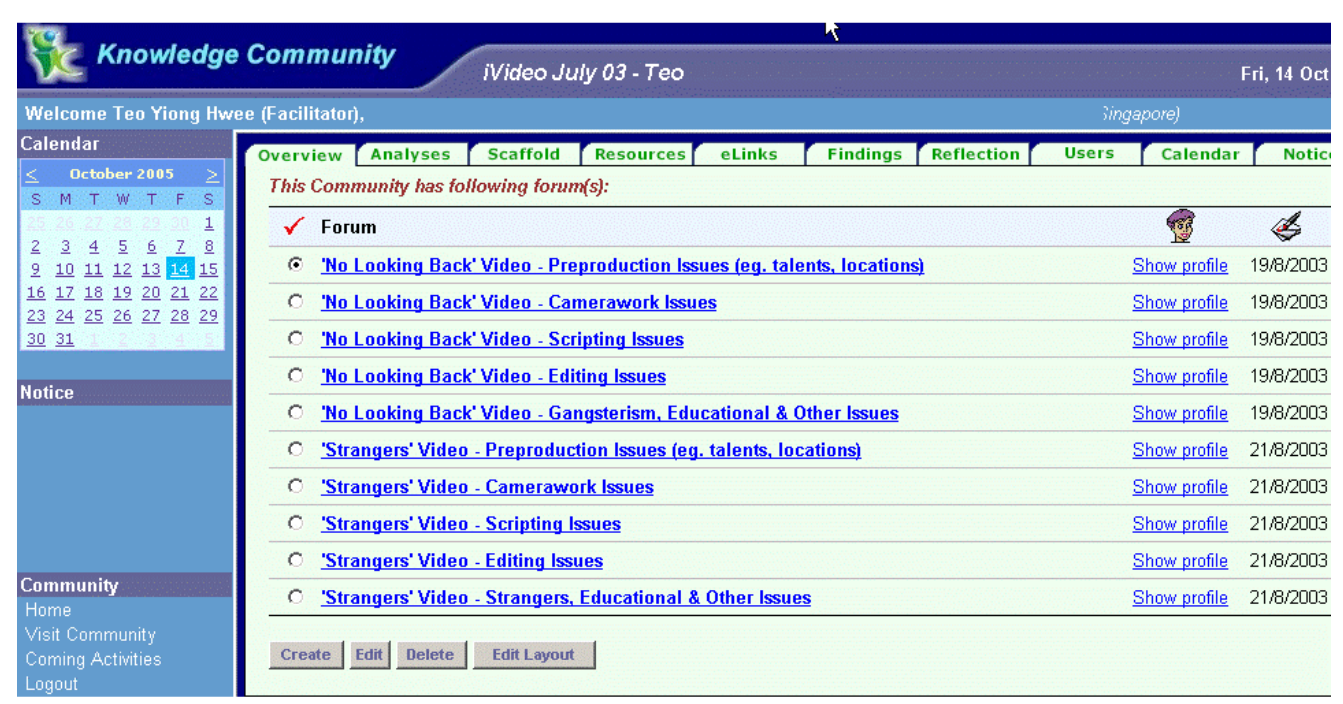

Figure 1. Discussion forums for two videos "No looking back" and "Strangers"

Not knowing what issues to discuss

"Not knowing what issues to discuss" is a common problem among novice learners as they do not possess sufficient content knowledge. To address this problem, conceptual scaffolding in the form of topic forums, was provided to prompt learners on the issues to discuss. Conceptual scaffolding assist learners in deciding what to consider or to priortise what is important (Hill \& Hannafin, 2001).

Five topic forums were created for each of the 2 video cases, "No Looking Back" and "Strangers": (a) Preproduction Issues (e.g., choice of talents, location, preparation for shooting); (b) Camerawork Issues (e.g., camera techniques, angles, lighting, directing); (c) Scripting Issues. (e.g., scripting and characterisation); (d) Editing Issues. (e.g., video editing, audio editing, choice of music and effects); and (e) Educational and Other Issues. (e.g., how the video could be used by teachers and any other issues not covered in the first four forums) (see Figure 1).

Not knowing how to discuss

To address the third problem of "Not knowing how to discuss", procedural scaffolding was provided to support the procedure of collaborative critiquing by the creation of four critique threads.

Four separate threads, each corresponding to a critique step, were set up for them to contribute suggestions within each forum topic.

Thread 1: assess whether video has achieved purpose for target audience

Thread 2: justify strengths and suggest improvements 
Thread 3: justify weaknesses and suggest improvements

Thread 4: summarise important points for transfer to own project

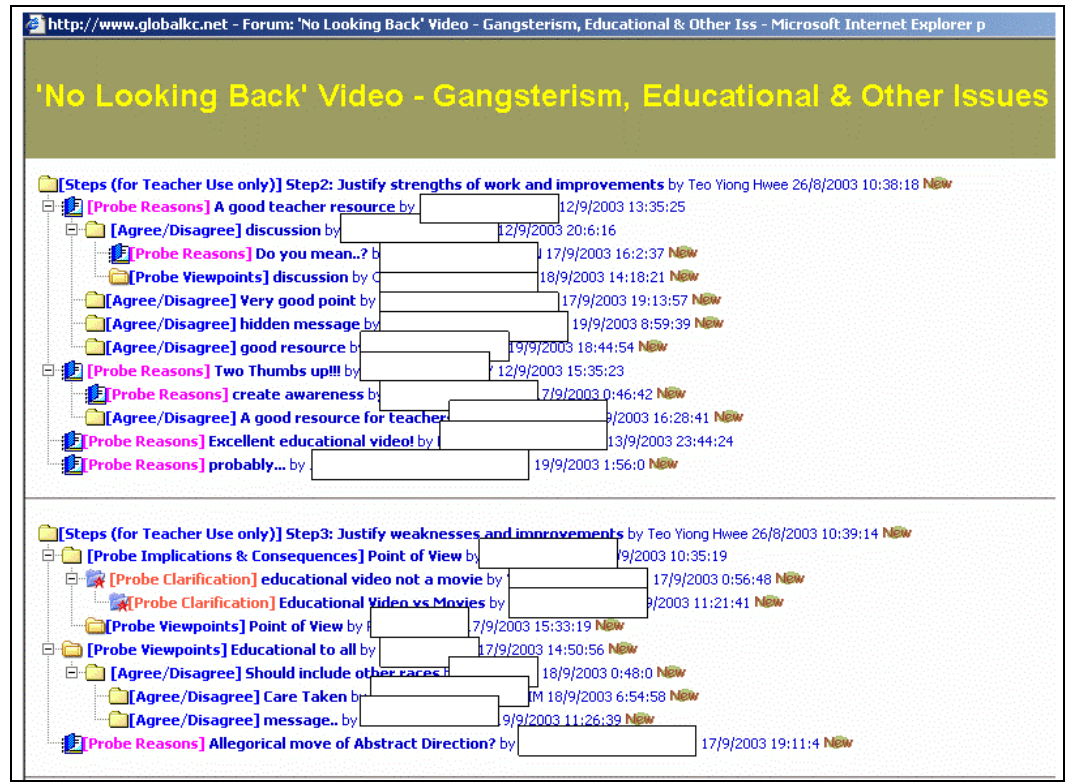

Figure 2. Threaded discussion in KC (showing steps 2 and 3 threads)

The difference between conceptual and procedural scaffolding is that the former focuses on what issues to discuss whereas the latter focuses on how issues are to be discussed. Figure 2 shows how message postings pertaining to critique threads two and three were indented in chronological order for the topic forum "No Looking Back Video - Other Issues".

While creating topic forums to prompt discussion in content areas is not something new, the focus here is to examine to what extent such forums together with procedural threads on critiquing, could scaffold learners to acquire knowledge. In this study, metacognitive scaffolding and strategic scaffolding are provided through the use of sentence openers. To help students think (metacognitive scaffolding), sentence openers designed included "I am looking from the point of view of", "The assumptions are". In addition to helping students think, some sentence openers also prompt them on different ways to do a task (strategic scaffolding), for example "An improvement to your suggestion is". Due to space constraint, this paper focuses on conceptual and procedural scaffolding. Having described the design features that were used in $K C$ to overcome the obstacles of not motivated by discussion topic, not knowing what issues to discuss, and not knowing how to discuss, the next section elaborates on the methodology of the study.

\section{Methodology}

Two research questions guided this study:

1. To what extent did the 4-step critique model assist participants in their learning? 
2. How did participants perceive the value of critiquing video examples in helping them learn about video production?

Three data sources were used to answer the research questions. They were the content of online discussion, an online survey and participant interviews. The discussion was exported and archived in Word document and spliced into units of message idea to be content-analysed. A message idea is a unit of meaning or idea. In most cases, a message idea corresponded to a paragraph. When two paragraphs dealt with the same unit of meaning or idea, they were counted as one unit. But when one paragraph contained two ideas, it was counted as two separate units.

An online survey elicited participants' feedback on three dimensions: learning from online discussion; learning from video production; and learning from critiques. The anonymous survey was administered at the end of the unit and consisted of 11 quantitative items and 11 open-ended essay type items. The quantitative questions were Likert-scale type items measuring the perceived benefits of asynchronous discussion. As this study is mainly a qualitative inquiry, the intent of administering the quantitative items was to get a feel of the extent of agreement or disagreement on certain issues and not to generalize beyond the small sample size of 42 .

The third source of data was from the semi-structured interviews. This approach allowed the researcher to seek understanding by exploring and probing participants' viewpoints in an open but structured environment. Each interview lasted for about 45 minutes and was audio taped to assist in accurately capturing all responses. Verbatim transcriptions from the audio recordings were then made. Seven participants were randomly selected for interview on their online critique experience including interface issues and how their groups worked together in accomplishing the video project. The interviews also solicited participants' views on some of the items in the online survey and offered another source for triangulation. To maintain reliability of coding, the data sources were also coded by a second coder but for voluminous message transcripts, it is common practice to do inter-rater coding for part of the total transcripts. In our case, about $20 \%$ (or 240 messages of 1181 message ideas) were inter-rater coded. Prior to coding, the second coder was given preliminary training explaining the research, the meaning and purposes of the indicators. A practice session was conducted by the author and second coder on 30 transcripts from the online discussion. Any doubts and clarifications were ironed out before mutual agreement was arrived at in relation to the coding of the practice transcripts. Once the percent agreement between the two coders reached $80 \%$, independent coding began.

\section{Findings}

Findings are organised according to the two research questions.

\subsection{Question 1: To what extent did the 4-step critique model assist students in their learning?}

Student engagement in the procedure of online critiquing was measured using two dimensions: quantity and quality.

\section{Quantity}

The 42 pre-service teachers generated a total of 874 postings consisting of 1181 message ideas within a four-week period over ten forums (five forums for each of the two video examples). Two indicators were used to measure quantity of contribution: 
participation of individuals and volume of posting in each of the critique steps. In terms of participation of individuals, the four critique steps attracted a large proportion of preservice teachers to participate for each of the steps (each of the 4 steps attracted $97.6 \%$ to $100 \%$ of participants). In terms of volume of postings received (Figure 3), Step 3 (analysing weaknesses) attracted most of the postings $(50.9 \%)$, followed by step 2 (analysing strengths) (32\%).

This indicates that participants had no problems identifying and discussing the strengths and weaknesses of the two videos. However, step 1 (whether video met its purpose for its audience) and step 4 (summarise important points for transfer to own project) received the lowest number of postings $(5.5 \%$ and $10.1 \%)$. A possible reason why steps 1 and 4 received comparatively far fewer postings was that these steps were more demanding tasks requiring inference (step 1) and summarizing (step 4) which novices seemed to be weak at.

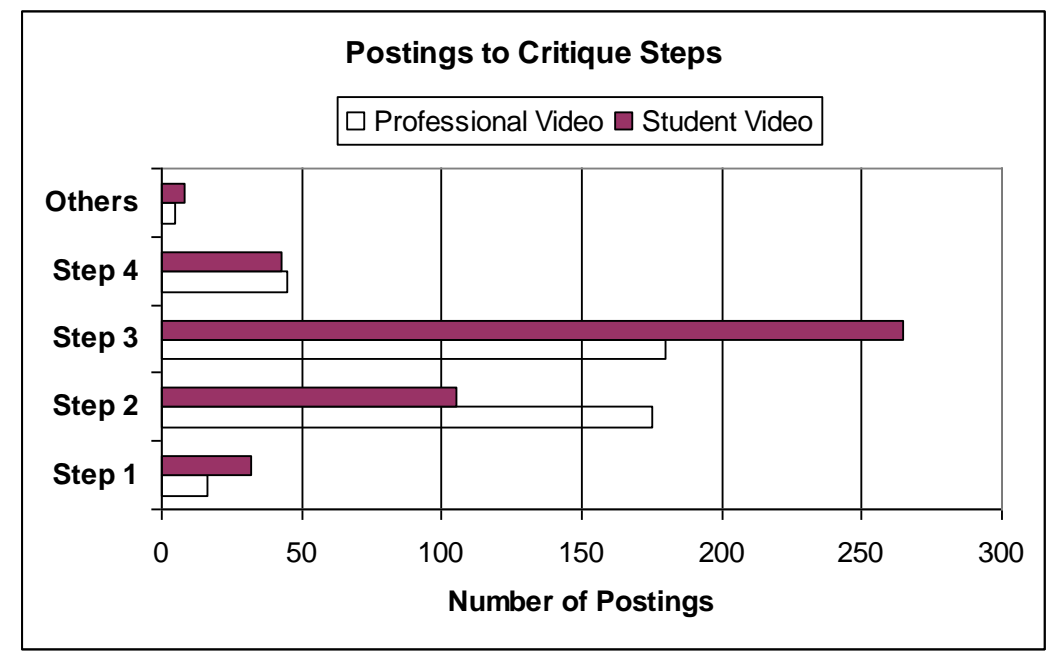

Figure 3. Number of postings for each critique step

Quality

Quality of online discussion was measured using different indicators by different researchers, depending on the research question. For this study, the following four indicators were used to measure the quality of discussion:

1. Was the discussion on task?

2. Was the discussion relevant to the thread?

3. Was the discussion in-depth?

$4 \quad$ How did students perceive the use of the four-step critique model?

For the first indicator, discussion was coded on-task if it related to the learning objectives of the course. Content analysis of the 1181 message ideas revealed that $99.5 \%$ (1175) were on task. As an illustration of the second indicator on relevancy, postings to the second critique step should focus on identifying strengths of the video examples and a message idea would deemed to have "changed focus" if it discussed weaknesses instead. It should have been posted to the third critique step meant for that. There was a very high percentage of relevant discussion (each of the 4 steps recorded between $96 \%$ and $99 \%$ relevancy). Participants' feedback in the survey open-ended question asking them for their views on the use of the critique steps revealed that the critique steps helped 
participants focus their thoughts.

For the third indicator of in-depth discussion, Henri's (1992) coding of level of information processing was used. This involved classifying a statement as "surface" or "in-depth". A surface statement is an utterance "repeating what has been said without adding any new elements" or "proposing solutions without offering explanations" (p.130). An in-depth statement refers to a message that reflects organisation and critical evaluation of information. Overall, $90.2 \%$ of the statement units were in-depth and $9.8 \%$ were surface. A reason for the high occurrence of in-depth messages may have been due to the use of sentence openers which prompted students' critical thinking (Teo \& Churchill, 2007). These openers (e.g. I am looking from the viewpoint of, An improvement to the suggestion is, The assumptions are, This suggestion might have consequences of, I agree that, I do not agree that) helped participants to probe each other's comments from different viewpoints by offering ways to start their message postings.

As a fourth indicator of quality, participants' perceptions of the use of the 4-step critique model were obtained from interviews and an anonymous online survey. The feedback was predominantly positive. Participants wrote on how the 4-step critique model had assisted them to a large extent in: (a) focusing their thoughts; (b) keeping the discussion organised; (c) guiding writing and thinking; and (d) learning a critiquing procedure.

(Focusing thoughts)

It's appropriate. Because you focus on one aspect first. Your thoughts don't jumble up. (Interview I13; M13.3)

(Keeping discussion organized)

These steps are good. It helps to organise the online discussion. Without these steps, all the discussion will be scattered in one page. (Survey 16.14)

(Guiding writing and thinking)

The collaborative online critique enables us to critique with more planning and thought. (Survey 16.6)

(Learning a critiquing procedure)

It gives us a clearer picture as to which areas we have to look into for critiquing. Our critique would then be more well-rounded as we are still very new to critiquing. (Survey 16.41.1)

3.2 Question 2: How did students perceive the value of critiquing video examples in helping them learn about video production?

Perceptions of the value of critique were obtained from participant interviews and anonymous online survey conducted at the end of the module.

Knowledge of what makes a good video

In the post-online survey, participants were asked how they rated their knowledge of what makes a good educational video before and after the online critique (on a Likert scale: 1 = Very Poor; 2 = Poor; 3 = Average; $4=$ Good; 5 = Very Good) (see Figure 4). It appears that most gained much knowledge on the various aspects of educational video production after the online critique activity. For example, those who felt their knowledge was Good or Very Good increased from $29 \%(24 \%+5 \%)$ before the critique activity, to $87 \%(58 \%+29 \%)$ after the critique. 


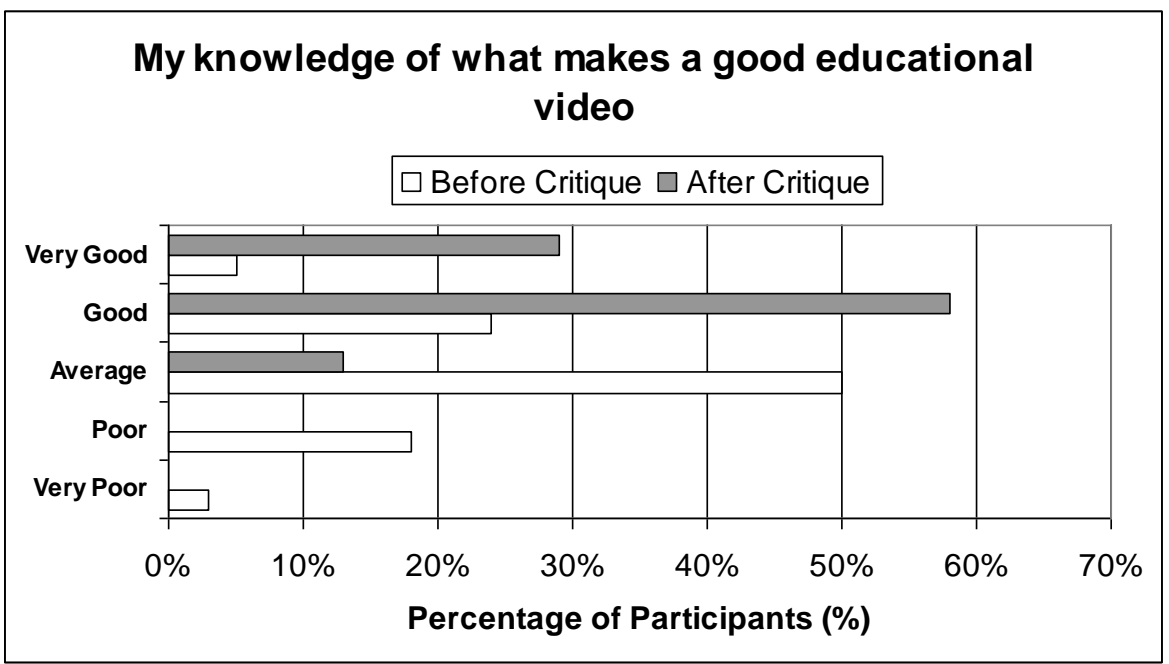

Figure 4. Student responses to survey question "My knowledge of what makes a good education video after critique ...."

In addition, participants' gave very positive views on how critiquing professional example and past student example has helped them in their learning and these are described next.

Value of critiquing a professional video example

To the survey questions, "Seeing and discussing professional video example is a good way to define what low and high quality work look like", and "Seeing and discussing student video example is a good way to define what low and high quality work look like", all participants either agreed or strongly agreed that the two video examples had helped them define standards of quality in production. None disagreed. For the professional video, a student recounted in the interview how the professional video set a high standard for their team's production:

I believe that when you look at something that is better, you can work towards it. (Interview 11; A5-1; JW11.3)

Value of critiquing a student video example

Interestingly, participants found the student video example (SV) even more beneficial in establishing standards than the professional video example (PV) $(71.8 \%$ Strongly Agreed for SV compared with $33.0 \%$ for PV). This result from the survey was similarly supported by the interview data where three times more interviewees expressed that the student video benefited them more in avoiding making glaring mistakes of production:

From the student video, I learnt to avoid [doing], whereas the No Looking Back [professional video], will be on the do's to incorporate. (Interview 11; A5; DY11.2-11.3)

The video examples set a benchmark for participants on what constituted good and bad production. To triangulate participants' perceptions, the content analysis of the online discussion log data revealed that the novice teachers could:

1. apply what they learnt from class lessons to the discussion;

2. comment on both strengths and weaknesses of the two videos;

3. offer expertise that went beyond what they learnt in class;

4. contribute suggestions on how to improve the production techniques 
concerning preproduction, camerawork, scripting, editing and other issues;

5. debate conflicting viewpoints and learn from the cognitive conflict.

\section{Discussion and Conclusion}

This paper focuses on how to engage novice learners in collaborative critiquing of professional work and past student work before learners embark on their video production projects. The benefits of online collaborative critiquing have been discussed from its underpinning in social constructivism and situated cognition theories. To overcome the three obstacles of asynchronous online discussion (unmotivated by discussion topic, not knowing what and not knowing how to discuss), participants critiqued authentic and relevant video examples as an anchor, and different topic forums and critique threads were created respectively as conceptual and procedural scaffolding in the online discussion platform.

In summary, the findings to research question one (To what extent did the 4-step critique model assist students in their learning) revealed that each of the 4 critique threads attracted nearly full participation from the preservice teachers, and that $83 \%$ postings were related to discussion of strengths and weaknesses of the two videos. An implication is that future online critique designers could encourage more participation in areas that require novices to reflect or think deeper (example, critique steps 1 and 4).

Findings to research question two (How did students perceive the value of critiquing video examples in helping them learn about video production?) revealed three advantages of critiquing video examples. First, students gained more knowledge on the various aspects of educational video production after the online critique activity. Second, the use of video examples set benchmarks and standards for students to follow. While both videos were beneficial to students, participants found that they benefited more from the student video as they could relate to it more. Learning from people's mistakes help make the relevancy of design principles more apparent to novices. Third, critiquing video examples connected participants with their own video production experience as they could infer on their own, what they should and should not do. This is a distinct advantage of online collaborative critiquing as students can relate better with principles they discover for themselves than if taught didactically to them.

This study has demonstrated that carefully designed anchor topics in various content areas can provide conceptual scaffolding and different critique threads can provide procedural scaffolding to novice learners to acquire substantial knowledge. While the study involved a course on educational video production for preservice teachers, the strategies could be adapted for other skill-based subjects such as hypermedia, website creation and even subjects like languages and literature. In art education, different types of critiques have traditionally been designed to learn about the artist, the art critic, the art historian and the aesthetician (Hartung, 1995). Similarly, in teaching languages and literature, online topic forums can be created to provide conceptual scaffolding to discuss about characters, author, literary style, grammar, and the relevance of issues to real life. The four critique threads can be adapted for use in providing procedural scaffolding to guide students on how to critique. Critiques can be used to judge the students' progress by engaging the different perspectives of the teacher, the student's peers and the student. The above strategies can also be used for teacher education courses such as getting beginning teachers to share and debate issues concerning classroom management, classroom effectiveness, how to teach slow and quick learners, and how to motivate students. Novice teachers can critique video snippets 
of positive and negative instances of classroom practices and relate them to principles learned in class.

Asynchronous online discussion affords collaboration, discussion and learning anytime, anywhere without the risk of 'losing face' compared with face-to-face meetings. This will encourage everyone to participate and contribute ideas to an issue, which will be a challenge in our time-constrained classroom. Beside this, the online critique affords multiple perspectives for considerations. By interacting with others and capable peers, learning can occur first on the external level through socialisation, and scaffolding can help students to internalise their learning and help learners to perceive multiple perspectives. Perspectives that contradict a learner's original ideas generate socialcognitive conflict. Social-cognitive conflict can be an important ingredient in peer facilitation of learning. For example, pre-service teachers in this study discovered that they could learn much from their peers. A participant commented in the online survey that the collaborative critique managed to change her beliefs and style of video production:

Before I read [the online forums], I would have my own perspective on how to produce a video of my own style. But then some people comment that that kind of style is not suitable. So I take into consideration when I'm doing the [my] video. . . so we try to integrate what people like and what people don't like. (Interview 2; M2.2-2.3)

This demonstrates the power of social negotiation in mediating social-cognitive conflict which leads to knowledge re-construction. Often times, the novices were able to contribute expert-like insights in their critiques. More importantly, learners tapped into the overlapping expertise of their peers to generate solutions to problems themselves without the teacher's help. It would be impossible for a single person or teacher to possess all the knowledge and answers to problems. Therefore this online collaborative learning can be richer than learning from a single teacher and may help to shorten a novice learner's learning curve.

\section{Limitations and future works}

It should be noted that the context in which this study took place was one of pre-service teacher education environment in Singapore. The culture and context of the teacher education institution may limit the application of the findings to other non-Singapore teacher education sites. Another limitation was that being a teacher education institution, there were more female participants $(73.8 \%)$ than male. This gender composition may not be representative of other contexts. We would also prefer to have all (instead of 20\%) the message ideas inter-rater coded if we have less budget constraints.

While this study shows how novices could learn design principles from critiquing other people's works in an online discussion, future studies could focus on longitudinal research to track whether these novices transfer their learning from the critique forums to their own work. The factors contributing to their successful or unsuccessful transfer would lead to new ways to help novice designers to move towards expertise.

\section{References}


1 Barrett, T. (2000). Studio critiques of student art: As they are, as they could be with mentoring. Theory into Practice, 39(1), 29-35.

2 Brown, J. S., Collins, A., \& Duguid, P. (1989). Situated cognition and the culture of learning. Educational Researcher, 18(1), 32-42.

3 Chai, C.S., \& Tan, S.C. (in press). Professional development of teachers for computer-supported collaborative learning (CSCL) through Knowledge Building. Teacher College Records.

4 Chai, C.S., \& Tan, S.C. (2006). Computer-Supported collaborative learning for knowledge creation. In M.S. Khine \& D. Fisher (Eds.), Contemporary approaches to research on learning environments: World views. (pp. 579-602). Singapore: World Scientific.

5 Chi, M. T. H. \& Bassock, M. (1989). Learning from examples via self-explanation. In L. Resnick, (Ed.). Knowing, learning and instruction: Essays in honour of Robert Glaser (pp. 251-282). Hillsdale, NJ: Lawrence Erlbaum Assoc.

6 Conati, C., \& Vanlehn, K. (2000). Toward Computer-Based Support of MetaCognitive Skills: a Computational Framework to Coach Self-Explanation. International Journal of Aritificial Intelligence in Education, 11, 389-415.

7 Cook, J. (2000). Cooperative problem-solving dialogues in learning. In G. Gautier, C. Fransson \& K. Van Lehn (Eds.), Intelligent tutoring systems (pp. 615-624). Berlin: Springer.

8 Feldman, E. B. (1994). Practical Art criticism. Englewood Cliffs, NJ: Prentice Hall.

9 Groeling, T. (1999). Virtual discussion: Web-based discussion forums in Political Science. Paper presented at the 1999 National convention of the American Political Science Association, Atlanta, Georgia.

10 Guzdial, M. (1994). Software-realized scaffolding to facilitate programming for science learning. Interactive Learning Environments, 4, 1-44.

11 Guzdial, M., \& Turns, J. (2000). Effective discussion through a computer-mediated anchored forum. The Journal of the Learning Sciences, 9(4), 437-469.

12 Hartung, E. S. (1995). The many faces of critique. School Arts, 95(4), 36-37.

13 Henri, F. (1992). Computer conferencing and content analysis. In A. R. Kaye (Ed.), Collaborative learning through computer conferencing: The Najaden papers (pp. 117-136). Berlin: Springer-Verlag.

14 Hernandez-Serrano, J., \& Jonassen, D. (2003). The effects of case libraries on problem solving. Journal of Computer Assisted Learning, 19, 103-114.

15 Hill, J. R., \& Hannafin, M. J. (2001). Teaching and learning in digital environments: The resurgence of resource-based learning. Educational Technology Research \& Development, 49(3), 37-52.

16 Hoadley, C., \& Kim, D. E. (2003). Learning, Design, and Technology: Creation of a design studio for educational innovation. In A. Palma dos Reis \& P. Isaís (Eds.), Proceedings of the IADIS International Conference e-Society 2003 (pp. 510-519). Lisbon, Portugal: IADIS.

17 Howe, C., \& Tolmie, A. (1998). Computer support for learning in collaborative contexts: prompted hypothesis testing in physics. Computers \& Education, 30, 233 235 .

18 Hsi, S. H.-R. (1997). Facilitating knowledge integration in science through electronic discussion: The Multimedia Forum Kiosk. Unpublished PhD dissertation, University of California, Berkeley. 
19 Jonassen, D., Howland, J., Marra, R., \& Crismond, D. (2008). Meaningful learning with technology (3rd ed.). Upper Saddle River, NJ: Pearson.

20 Lave, J., \& Wenger, E. (1999). Legitimate peripheral participation in the communities of practice. In R. McCormick, \& C. Paechter (Eds.), Learning and knowledge. (pp. 21-35). Thousand Oaks, CA: SAGE Publication.

21 Lazonder, A. W., Wilhelm, P., \& Ootes, S. A. W. (2003). Using sentence openers to foster student interaction in computer-mediated learning environments. Computers \& Education, 41, 291-308.

22 Moore, D. (1993). Dialogue games for intelligent tutoring systems. Unpublished doctoral dissertation, Leeds Metropolitan University.

$23 \mathrm{Ng}$, C. S. L., Cheung, W. S., \& Hew, K. F. (in press). Solving ill-structured problems in asynchronous online discussions: Built-in scaffolds vs. no scaffolds. Interactive Learning Environment.

24 Powers, B. (1992). Instructor excellence: Mastering the delivery of training. San Francisco: Jossey-Bass.

25 Reid, S. (2002). The Prentice Hall guide to college writers (6th ed.): Prentice Hall.

26 Reist, K. (2005). Critiquing vs debriefing. School Arts, 104(9), 30.

27 Scardamalia, M., \& Bereiter, C. (1991). Higher levels of agency for children in knowledge building: A challenge for the design of new knowledge media. The Journal of the Learning Sciences, 1(1), 37-68.

28 Scardamalia, M., \& Bereiter, C. (2006). Knowledge building: Theory, pedagogy, and technology. In K. Sawyer (Ed.), The Cambridge handbook of the Learning Sciences (pp. 97-115). New York, NY: Cambridge University Press.

29 Schwartz, D. L. (1995). The emergence of abstract representations in dyad problem solving. The Journal of the Learning Sciences, 4, 321-354.

30 Sweller, J., \& Cooper, G. A. (1985). The use of worked examples as a substitute for problem solving in learning algebra. Cognition and Instruction, 2, 58-89.

31 Teo, Y. H. \& Churchill, D. (2007). Using sentence openers to support students' argumentation in an online learning environment. Educational Media International, 44(3), 207-218.

32 Thomas, J. W., \& Mergendoller, J. R. (2000). Managing project-based learning: Principles from the field. Paper presented at the Annual Meeting of the American Educational Research Association, New Orleans.

33 Trumbo, J. (1997). The process of critique in visual communication. Journalism \& Mass Communication Educator, 52(2), 15-23.

34 Vygotsky, L. S. (1978). Mind in society. Cambridge, MA: Harvard University Press.

35 Wang, Q., \& Woo, H. L. (2007). Comparing asynchronous online discussions and face-to-face discussions in a classroom setting. British Journal of Education Technology 38(2), 272-286.

36 Wu, A. (2003). Supporting electronic discourse: Principles of design from a social constructivist perspective. Journal of Interactive Learning Research, 14(2), 167184. 